\title{
Predictors of depression and anxiety among caregivers of hospitalised advanced cancer patients
}

\author{
Aytül Karabekiroğlü ${ }^{1}$, MD, Esra Yancar $\underline{\text { Demir }}^{2}$, MD, Servet $\underline{A k e r}^{3}$, MD, Birsen Kocamanoğlü ${ }^{4}$ MD, Gamze Sırmalı Karabulut ${ }^{5}$
}

\begin{abstract}
INTRODUCTION Cancer is a chronic disease that requires long-term treatment and care. Caregivers of cancer patients are at greater risk of developing depression than the general population. The effect of caregivers' cognitive flexibility on depression and anxiety has not been well studied. We aimed to investigate the social characteristics, burden levels and cognitive flexibility of caregivers of advanced cancer patients, and determine the relationship between these factors and depression and anxiety. We hypothesised that factors such as cognitive flexibility and caregiver burden level significantly predict anxiety and depression.

METHODS The study included 69 primary informal caregivers of patients with Stage 4 cancer. Methods utilised included diagnostic semi-structured interviews, Beck Depression Inventory (BDI), Beck Anxiety Inventory (BAI), Zarit Caregiver Burden Inventory and cognitive flexibility inventory.

RESULTS BDI scores were found to be significantly higher in caregivers who cared for men compared to those who cared for women $(20.44 \pm 2.06$ vs. $13.29 \pm 1.81 ; t=2.60 ; p=0.01)$. BDI mean scores were statistically lower in caregivers who received help with caregiving compared to those who did not $(t=2.62 ; p=0.01)$. Cognitive flexibility level, burden level and lack of social support were found to be predictors of caregiver depression.

CONCLUSION The study showed that individuals with low cognitive flexibility levels are more likely to have depressive and anxiety symptoms. Based on our findings, we opine that evaluations of caregivers' cognitive strategies and social support are needed to determine the risk of depression in caregivers of cancer patients.
\end{abstract}

Keywords: anxiety, cancer, caregiver, cognitive flexibility, depression

\section{INTRODUCTION}

A cancer diagnosis changes not only the patient's life, but also that of the family members. Cancer is a chronic disease that requires long-term treatment and care. Cancer patients need care both psychologically and physically, especially during the terminal phase of the illness. A caregiver can be defined as a spouse, adult child, relative, partner or friend who has a personal relationship with, and provides a broad range of unpaid assistance for, an adult with a serious illness. ${ }^{(1)}$ Several studies have found that cancer patients and their partners report higher levels of psychological distress as compared to the general population..$^{(2,3)}$

In some studies, family caregivers of cancer patients were found to have more psychological problems and poorer quality of life than the patients for whom they cared. ${ }^{(4-6)}$ These caregivers have a higher risk of developing depression than the general population. Ramirez et al reported that in the year before the death of a cancer patient, the estimated prevalence rates of anxiety and depression among informal caregivers were high, at $46 \%$ and $39 \%$, respectively. ${ }^{(7)}$ Commonly reported risk factors for caregiver anxiety and depression are female gender, spousal relationship to the recipient of care, high perceived caregiver burden, financial problems, familial conflict, poor patient performance status, duration of illness, lung cancer diagnosis and palliative treatment intent. ${ }^{(8-10)}$

Caregiving demands are divided into three categories: physical, emotional and financial. ${ }^{(11)}$ These demands can be burdensome to the caregiver. The concept of caregiver burden has both objective and subjective dimensions. Objective dimensions include the amount of time spent in caregiving, the type of caregiving services provided and any financial resources expended on the patient. ${ }^{(12,13)}$ Subjective dimensions address an individual's beliefs, assumptions and feelings about the caregiver role. ${ }^{(14)}$ Caregivers must cope with physical, emotional, social and financial issues, which may result in the neglect of their own needs. ${ }^{(15,16)}$ Caregiver burden has been reported to be a risk factor for depression. ${ }^{(17)}$ Caregivers' anxiety and depressed mood can also exert an adverse effect on their perceptions of their current situation. ${ }^{(18,19)}$

Kim et al suggested that caregivers do derive benefits from their caregiving role, including acceptance, empathy, appreciation, positive self-image and reprioritisation. ${ }^{(20)}$ Haley et al's study showed that caregivers who found meaning and subjective benefits from caregiving were less likely to be depressed and reported greater satisfaction with life. ${ }^{(21)}$ The aforementioned studies also stated that a caregiver's perceptions can have an impact on their risk of depression and anxiety.

Cognitive flexibility can be defined as the ability to adapt to new and unexpected conditions in the environment. ${ }^{(22)}$ In neuroscience, this term is sometimes referred to as 'attention switching', 'cognitive shifting' or 'mental flexibility'. Cognitive flexibility includes the ability to change an individual's thinking, 
emotions and behaviours according to the demands of new life events, and is useful in helping people adapt to novel scenarios and information such as moving to a foreign country, or encountering unexpected demands in the workplace or lastminute change of plans. The term 'resilience' is generally defined as the ability to quickly return to the previous good condition. The term 'cognitive inflexibility' is used to describe a person who needs to adapt to changes in the environment but fails to do so. People with low cognitive flexibility tend to apply the same patterns that were shown to be effective for them in previous situations. However, when familiar behavioural patterns are applied to new situations, they often prove to be ineffective.

Family caregivers of cancer patients may be forced to make changes in their own lives, take on new roles and responsibilities, or give up past activities. ${ }^{(23)}$ These life changes are often perceived as stressors that can increase the caregivers' burden and strain. ${ }^{(24)}$ It is hypothesised that individuals who adapt well to new life situations are less likely to develop depression than those who lack such adaptability. However, cognitive flexibility and its impact on depression have not been well studied in caregivers of cancer patients. In this study, we aimed to determine the social characteristics, caregiver burden levels and cognitive flexibility of caregivers of advanced cancer patients. We also aimed to determine the relationship between these parameters and caregivers' depression and anxiety levels. We hypothesised that factors such as cognitive flexibility and caregiver burden level can significantly predict caregiver anxiety and depression.

\section{METHODS}

Primary informal caregivers of Stage 4 cancer patients were included in the study. All patients were above 18 years of age, diagnosed with advanced cancer (i.e. presence of distant metastases that were histologically and/or pathologically confirmed), and received inpatient palliative radiotherapy between May and October 2015 in an oncology centre in Samsun, Turkey. A primary family caregiver was defined as a family member or a significant other whom the patient considered as the main provider of unpaid care. All eligible caregivers were staying in the hospital as the patients' companion and were not undergoing psychiatric treatment at the time of the study. The institutional review board of the Samsun Education and Research Hospital, Turkey, approved the study. Participants were assured anonymity and confidentiality, and all gave their written consent to participate in the study.

The study utilised semi-structured interviews and self-reported questionnaires. A psychiatrist or psychologist conducted the semi-structured interviews, and self-reported questionnaires were administered to the caregivers after the interviews. Semi-structured interviews included detailed questions about the caregivers' sociodemographic characteristics, social life, economic status, their knowledge of the disease, time elapsed since diagnosis and the patient's needs. Social support was also evaluated during the interviews. We also asked about the demands of the patient, including whether the patient required financial assistance and help with psychological or physical issues.
The Beck Depression Inventory (BDI), a 21-item self-reported questionnaire that assesses depression levels, ${ }^{(25)}$ was administered to all caregivers. The total score of the BDI ranges from 0 to 63, with higher scores indicating higher levels of depressive symptoms. Caregivers were also administered the Beck Anxiety Inventory (BAI), a 21-item, multiple-choice self-reported inventory that measures the severity of anxiety in adults and adolescents. ${ }^{(26)}$ The validity and reliability of the Turkish version of the BDI and BAI have been assessed by Hisli ${ }^{(27)}$ and Ulusoy, ${ }^{(28)}$ respectively.

The burden level of caregivers was determined using the Zarit Caregiver Burden Inventory (ZCBI). ${ }^{(29)}$ This 19-item self-reported inventory consists of response options ranging from 0 ('never') to 4 ('nearly always'). The Turkish version of this scale was found to be valid and reliable by Özlü et al. ${ }^{(30)}$ In addition, the caregivers were administered the cognitive flexibility inventory (CFI), a brief self-reported measure of the type of cognitive flexibility that is necessary for individuals to successfully challenge and replace maladaptive thoughts with more balanced and adaptive thinking. ${ }^{(31)}$ Gülüm and Dağ have assessed the validity and reliability of the Turkish version of the CFI. ${ }^{(32)}$

Variable distributions were examined for normality using the Kolmogorov-Smirnov test. The $t$-test and variance analysis were used to compare the mean values of BDI and BAI. Pearson analysis was used to determine the relationship power between continuous variables. We used multiple regression analysis (forward method) to evaluate the effect of independent values on $\mathrm{BDI}$ and BAI. All values were expressed as percentages or mean \pm standard deviation. A p-value $\leq 0.05$ was considered to be statistically significant. SPSS version 13.0 (SPSS Inc, Chicago, IL, USA) was used for all statistical calculations.

\section{RESULTS}

A total of 69 family caregivers were included in the study. Tables I \& II show some of the characteristics of the caregivers and patients, respectively. Almost half of the caregivers (49.3\%, $\mathrm{n}=34)$ lived in the city centre, while the rest were either in towns $(30.4 \%, \mathrm{n}=21)$ or rural areas $(20.3 \%, \mathrm{n}=14)$. When asked about the demands of the patient for whom they were caring, $88.4 \%(n=61)$ of caregivers reported having to help the patient physically, while $78.3 \%(n=54)$ and $34.8 \%(n=24)$ of caregivers reported giving the patient psychological and financial assistance, respectively. $73.9 \%$ of caregivers lived with the patient and they were together throughout the day. The total mean scores for patients' personal care ability were $30.0 \pm 1.71$ for female patients and $27.53 \pm 1.42$ for male patients, with no significant difference between the genders $(t=1.091 ; \mathrm{p}=0.982)$.

Caregivers' depression and anxiety levels were measured using BDI and BAI, respectively. Their BDI and BAI mean scores were $17.95 \pm 1.53$ and $18.42 \pm 1.88$, respectively. Table III shows the results of comparisons between the caregivers' BDI and BAI mean scores and their sociodemographic variables. BDI mean scores were found to be significantly higher in caregivers who took care of male cancer patients compared to those who cared for female patients $(20.44 \pm 2.06$ vs. $13.29 \pm 1.81 ; t=2.60$; $\mathrm{p}=0.01$ ). BDI mean scores were significantly lower in caregivers 
Table I. Sociodemographic characteristics of caregivers $(n=69)$.

\begin{tabular}{|ll|}
\hline Variable & No. (\%) \\
\hline Gender & $15(21.7)$ \\
\hline Male & $54(78.3)$ \\
\hline Agemale & \\
\hline Marital status & $44.44 \pm 1.64$ \\
\hline Married & $59(85.5)$ \\
\hline Single/divorced & $10(14.5)$ \\
\hline No. of children* & $2.28 \pm 0.21$ \\
\hline Education & \\
\hline$\leq 8$ yr & $46(66.7)$ \\
\hline$>8$ yr & $23(33.3)$ \\
\hline Employed & $13(18.8)$ \\
\hline Relationship to patient & $22(31.9)$ \\
\hline Partner & $35(50.7)$ \\
\hline First-degree relative (parent/child) & $12(17.4)$ \\
\hline Second- or third-degree relative & $25(36.2)$ \\
\hline Having $\geq 1$ medical illness & $51(73.9)$ \\
\hline Living with the patient & $48(69.6)$ \\
\hline Having someone to help in caregiver role & \\
\hline
\end{tabular}

*Data presented as mean \pm standard deviation.

who received support from others in caregiving, compared to those who did not have any support $(t=2.62 ; \mathrm{p}=0.01)$.

$\mathrm{BAI}$ mean scores were significantly higher in caregivers who: (a) took care of male patients compared to those who cared for women $(21.02 \pm 2.57$ vs. $13.54 \pm 2.20 ; t=2.20 ; \mathrm{p}=0.03)$; (b) had medical illness compared to those who did not have illness (23.62 \pm 3.20 vs. $20.45 \pm 2.38 ; t=2.26$; $p=0.03)$; and (c) lived with the patient compared to those who lived apart from the patient $(20.45 \pm 2.38$ vs. $12.66 \pm 2.07 ; t=2.46 ; \mathrm{p}=0.01)$. BAl mean scores were significantly lower in caregivers who received support from others in caregiving compared to those who did not $(14.68 \pm 1.91$ vs. $26.95 \pm 3.84 ; t=2.85 ; \mathrm{p}<0.001)$.

The correlations between $\mathrm{ZCBI}, \mathrm{BDI}, \mathrm{BAI}$ and $\mathrm{CFI}$ scores are shown in Table IV. The effects of independent variables on $\mathrm{BDI}$ and $\mathrm{BAI}$ were analysed using multiple regression analysis (forward selection) and the results are shown in Table V. Cognitive flexibility level, burden level and lack of social support were found to be predictors of caregivers' depression levels. We also observed that these three factors, together with the presence of medical illness in caregivers, play a role in predicting caregivers' anxiety levels. Thus, cognitive flexibility level, burden level and lack of social support could determine the depression variance (41\%) of caregivers (Table V).

\section{DISCUSSION}

Today, the scope of psychosocial care has been extended from cancer patients to their family members and caregivers. As cancer care moves increasingly into an outpatient setting, the role of family caregivers has also expanded. ${ }^{(33)}$ The psychological stress of caregiving has a negative impact on not only the health of family caregivers, but also the health and well-being of cancer
Table II. Sociodemographic characteristics of cancer patients $(n=69)$.

\begin{tabular}{|c|c|}
\hline Variable & No. (\%) \\
\hline \multicolumn{2}{|l|}{ Gender } \\
\hline Male & $45(65.2)$ \\
\hline Female & $24(34.8)$ \\
\hline 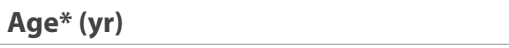 & $62.19 \pm 1.87$ \\
\hline \multicolumn{2}{|l|}{ Marital status } \\
\hline Married & $55(79.7)$ \\
\hline Single/divorced & $14(20.3)$ \\
\hline \multicolumn{2}{|l|}{ Cancer type } \\
\hline Respiratory system & $21(30.4)$ \\
\hline Central nervous system & $11(15.9)$ \\
\hline Gastrointestinal system & $16(23.2)$ \\
\hline Breast & $8(11.6)$ \\
\hline Genital system & $4(5.8)$ \\
\hline Urinary system & $3(4.3)$ \\
\hline \multicolumn{2}{|l|}{ Duration of illness (mth) } \\
\hline$<6$ & $27(39.1)$ \\
\hline 6 to 12 & $18(26.1)$ \\
\hline$>12$ to 24 & $13(18.8)$ \\
\hline$>24$ & $11(15.9)$ \\
\hline \multicolumn{2}{|l|}{ Personal care ability (dependence in) } \\
\hline Housework & $63(91.3)$ \\
\hline Cooking & $62(89.9)$ \\
\hline Shopping & $59(85.5)$ \\
\hline Climbing stairs & $47(68.1)$ \\
\hline Bathing & $41(59.4)$ \\
\hline Getting dressed & $40(58.0)$ \\
\hline Toileting & $39(56.5)$ \\
\hline Walking & $38(55.1)$ \\
\hline Eating & $28(40.6)$ \\
\hline Diagnosis of comorbid medical illness & $46(66.7)$ \\
\hline Having knowledge about the disease & $42(60.9)$ \\
\hline
\end{tabular}

*Data presented as mean \pm standard deviation.

patients. ${ }^{(34)}$ For these reasons, it is important to ensure that caregivers' psychological well-being is taken care of, as studies have shown that caregivers have a higher risk of depression and anxiety than the general population. ${ }^{(35)}$

In the present study, we found that caregivers of male cancer patients have statistically higher mean scores for BDI and BAI than those who cared for female patients. Bedard et al reported that even after controlling for other important determinants of burden, women who looked after male patients were at risk of experiencing excess role burden. ${ }^{(36)}$ Other authors have suggested that, in the area of caregiving, women are often assumed to be more capable of performing household and personal care tasks than men. ${ }^{(37)}$ Our study found that male patients may need more help in the area of personal care, and this factor could have an impact on their caregivers' depression and anxiety levels.

$\mathrm{BDI}$ and BAI mean scores in our study were statistically lower in caregivers who had help from others with the caregiver role as compared to those who had no help. Thus, lack of social 
support appears to be one of the predictors of depression and anxiety among caregivers. We also noted that a caregiver's burden level - both psychologically and physically - is further compounded by the lack of social support. Together, these factors can greatly increase the depression and anxiety levels of caregivers. In previous studies, a positive relationship was found between social support and psychological well-being. ${ }^{(38,39)}$ This is because support from others can provide a buffer against burden and stress by increasing the perception that resources are available to help manage the burden and stress. However, the relationship between support and depression is often complex. For instance, there can be differences between 'actual' and 'perceived' support. Furthermore, unwelcome support may be stressful instead of helpful for caregivers. ${ }^{(40)}$ In view of this, we had specifically asked caregivers about the 'perceived' support they were receiving.

Table III. Comparison of caregivers' BDI and BAI scores with sociodemographic characteristics of patients and caregivers.

\begin{tabular}{|c|c|c|c|c|}
\hline \multirow[t]{2}{*}{ Variable } & \multicolumn{2}{|c|}{ BDI } & \multicolumn{2}{|c|}{ BAI } \\
\hline & $t / F$ & p-value & $t / F$ & p-value \\
\hline \multicolumn{5}{|l|}{ Caregiver } \\
\hline Gender & 0.01 & $>0.05$ & 0.86 & $>0.05$ \\
\hline Marital status & 1.03 & $>0.05$ & 1.09 & $>0.05$ \\
\hline Education level (> 8 yr) & 2.90 & $<0.001$ & 2.49 & $<0.001$ \\
\hline Employment & 0.53 & $>0.05$ & 0.16 & $>0.05$ \\
\hline Diagnosis of medical illness & 1.18 & $>0.05$ & 2.26 & 0.03 \\
\hline Relationship to the patient & $1.77^{*}$ & $>0.05$ & $2.07^{*}$ & $>0.05$ \\
\hline Living with the patient & 1.70 & $>0.05$ & 2.46 & 0.01 \\
\hline Getting support from others & 2.62 & 0.01 & 2.85 & $<0.001$ \\
\hline \multicolumn{5}{|l|}{ Patient } \\
\hline Gender & 2.60 & 0.01 & 2.20 & 0.03 \\
\hline Marital status & 0.04 & $>0.05$ & 0.14 & $>0.05$ \\
\hline Cancer diagnosis & $1.62^{*}$ & $>0.05$ & $0.62^{*}$ & $>0.05$ \\
\hline Duration of illness & $0.22^{*}$ & $>0.05$ & $0.63^{*}$ & $>0.05$ \\
\hline Comorbid medical illness & 1.89 & $>0.05$ & 1.35 & $>0.05$ \\
\hline $\begin{array}{l}\text { Having knowledge about the } \\
\text { disease }\end{array}$ & 0.98 & $>0.05$ & 0.62 & $>0.05$ \\
\hline
\end{tabular}

*F-test was used to compare groups using analysis of variance. BAl: Beck Anxiety Inventory; BDI: Beck Depression Inventory
In the present study, caregivers' own medical illness was found to be a predictor of anxiety. Connell et al reported that caregivers who complained about the caregiving role were mostly concerned that their own health problems would interfere with the provision of care. ${ }^{(41)}$ Similarly, Rineldi et al observed that as the caregivers' age increased, so did their burden level, thus highlighting the importance of caregivers' medical illness. ${ }^{(42)}$ Additionally, caregivers' medical illness may increase the patients' anxiety level, due to the caregivers' difficulty in sustaining the substantial responsibilities of providing ongoing care.

In our study, caregivers' burden level was found to be a predictor of depression and anxiety, which is consistent with the findings of previous studies. ${ }^{(43,44)}$ Several factors, including caregivers' characteristics such as female gender, older age, unemployment, lower socioeconomic status, disease severity, and number and extent of demands for caregiving, can increase caregivers' burden level. ${ }^{(45-47)}$ Cultural expectations regarding the extent of involvement in the care of an ill family member have also been recognised as a potential moderator of the caregiving burden. ${ }^{(48)}$ In Turkey, family bonds are usually strong and family members are more likely to devote themselves to the care of the patient. This cultural aspect is seen in our study, where $73.6 \%$ of the caregivers lived with and accompanied the patient throughout the day. As there is limited research conducted in Turkey on the burden of caregivers of cancer patients, further studies are needed to understand and address caregivers' needs so that appropriate interventions can be introduced to reduce their caregiving burden. In our study, we did not find any correlation between CFI and ZCBI scores; this may be due to our small sample size.

In our study, cognitive flexibility was found to be a predictor of depression and anxiety in caregivers of cancer patients.

\section{Table IV. Correlations among ZCBI, BDI, BAI and CFI scores.}

\begin{tabular}{|c|c|c|c|c|}
\hline Variable & ZCBI & BDI & BAI & CFI \\
\hline ZCBI & & $0.404^{*}$ & $0.498^{*}$ & $-0.066^{\dagger}$ \\
\hline BDI & & & $0.767^{*}$ & $-0.453^{*}$ \\
\hline BAI & & & & $-0.426^{*}$ \\
\hline
\end{tabular}

${ }^{*} p<0.01 .+p>0.05$. BAI: Beck Anxiety Inventory; BDI: Beck Depression Inventory; CFI: cognitive flexibility inventory; ZCBI: Zarit Caregiver Burden Inventory

Table V. Multiple regression analysis of factors that affected scores of depression and anxiety.

\begin{tabular}{|c|c|c|c|c|c|}
\hline Independent variable & B & $\boldsymbol{\beta}$ & $t$ & p-value & $95 \% \mathrm{Cl}$ \\
\hline \multicolumn{6}{|l|}{ Depression level* } \\
\hline Cognitive flexibility inventory & -0.53 & -0.43 & 4.34 & $<0.001$ & $-0.77,-0.28$ \\
\hline Having someone who can help in caregiver role ${ }^{\ddagger}$ & -7.01 & -0.25 & 2.52 & 0.014 & $-12.56,-1.47$ \\
\hline Zarit Caregiver Burden Inventory & 0.18 & 0.23 & 2.31 & 0.005 & $0.02,0.34$ \\
\hline \multicolumn{6}{|l|}{ Anxiety level ${ }^{\dagger}$} \\
\hline Cognitive flexibility inventory & -0.61 & -0.40 & 4.39 & $<0.001$ & $-0.89,-0.33$ \\
\hline Zarit Caregiver Burden Inventory & 0.34 & 0.35 & 3.80 & $<0.001$ & $0.16,0.52$ \\
\hline Medical illness of caregiver ${ }^{\S}$ & 7.09 & 0.21 & 2.39 & 0.019 & $1.18,13.01$ \\
\hline Having someone who can help in caregiver role ${ }^{\ddagger}$ & -6.49 & -0.19 & 2.00 & 0.049 & $-12.97,-0.02$ \\
\hline
\end{tabular}

${ }^{*}$ Constant $=36.69$, multiple $\mathrm{R}=0.64$; multiple $\mathrm{R}^{2}=0.41$; Durbin-Watson $=2.184 ; \mathrm{p}<0.001$. + Constant $=28.93$; multiple $\mathrm{R}=0.71$; multiple $\mathrm{R}^{2}=0.47 ;$ Durbin-Watson $=$ 2.163; $p<0.001$. $\neq 0=$ having someone who can help in caregiver role; $1=$ not having someone who can help in caregiver role. $\S 0=$ no medical illness; $1=$ having at least one medical illness. $\beta$ : $\beta$ coefficient; $\mathrm{B}$ : B coefficient; $\mathrm{Cl}$ : confidence interval 
A diagnosis of cancer is life-changing for not only the patients, but also their caregivers, who often find themselves having to adapt to new life situations. Cognitive flexibility is an aspect of executive functioning. It is a trait or ability that allows an individual to consider multiple ideas, flexibly switch cognitive sets and inhibit habitual response patterns when environmental contingencies change. ${ }^{(49,50)}$ These processes seem to be important for successful implementation of cognitive restructuring, where the individual identifies a negative automatic thought, generates evidence that contradicts that thought, and subsequently generates a more adaptive or helpful way of interpreting the situation. ${ }^{(51,52)}$ Individuals who have difficulty adapting to new life situations are at risk of developing depression. The cognitive theory of depression states that depression is a result of automatic maladaptive cognitions. ${ }^{(53)}$ As cognitions become more adaptive, it is expected that depressed mood will be alleviated and that the overall level of functioning will increase. ${ }^{(54)}$ For instance, during cancer treatment, caregivers may have to deal with new living conditions (such as having to stay in the hospital as companions to the patient) that require them to display adaptive behaviours.

Our study had some limitations. First, it included only a small number of caregivers of hospitalised advanced cancer patients, and thus, our data cannot be generalised to all caregivers. Also, although the study has noted the importance of cognitive flexibility in relation to depression in caregivers, further follow-up studies are needed to determine the effect of cognitive interventions on caregivers' depression and anxiety levels.

In Turkey, people generally prefer to act as their family members' primary caregivers rather than leave their care to professional caregivers or care centres. Therefore, interventions to improve the well-being of caregivers are important. Caregivers should be encouraged to ask for help from other family members or friends whenever they feel overwhelmed by their caregiver role. ${ }^{(55)}$ In addition, positive coping strategies should be reinforced. Healthcare professionals can help caregivers to face new life situations as well as deal with negative behaviours. ${ }^{(56)}$ It may also be useful to evaluate the cognitive flexibility abilities of caregivers and establish cognitive interventions that address their needs.

\section{REFERENCES}

1. Given BA, Sherwood P, Given CW. Support for caregivers of cancer patients: transition after active treatment. Cancer Epidemiol Biomarkers Prev 2011; 20:2015-21.

2. Northouse L. A longitudinal study of the adjustment of patients and husbands to breast cancer. Oncol Nurs Forum 1989; 16:511-6.

3. Oberst MT, Thomas SE, Gass KA, Ward SE. Caregiving demands and appraisal of stress among family caregivers. Cancer Nurs 1989; 12:209-15.

4. McCorkle R, Siefert ML, Dowd MF, Robinson JP, Pickett M. Effects of advanced practice nursing on patient and spouse depressive symptoms, sexual function, and marital interaction after radical prostatectomy. Urol Nurs 2007; 27:65-77; discussion 78-80.

5. Mellon S, Northouse LL, Weiss LK. A population-based study of the quality of life of cancer survivors and their family caregivers. Cancer Nurs 2006; 29:12031 ; quiz 132-3.

6. Hodges LJ, Humphris GM, Macfarlane G. A meta-analytic investigation of the relationship between the psychological distress of cancer patients and their carers. Soc Sci Med 2005; 60:1-12.

7. Ramirez A, Addington-Hall J, Richards M. ABC of palliative care. The carers. BMJ 1998; 316:208-11.

8. Grunfeld E, Coyle D, Whelan T, et al. Family caregiver burden: results of a longitudinal study of breast cancer patients and their principal caregivers. CMAJ
2004; 170:1795-801.

9. Friðriksdóttir N1, Saevarsdóttir T, Halfdánardóttir Sí, et al. Family members of cancer patients: needs, quality of life and symptoms of anxiety and depression. Acta Oncol 2011; 50:252-8.

10. Rhee YS, Yun YH, Park S, et al. Depression in family caregivers of cancer patients: the feeling of burden as a predictor of depression. J Clin Oncol 2008; 26:5890-5

11. Ambigga Devi K, Sherina MS, Suthahar A. Depression and anxiety among family caregivers of cancer patients in an oncology clinic. Malays J Psychiatry 2005; 13:35-42.

12. Van Houtven $\mathrm{CH}$, Ramsey SD, Hornbrook MC, Atienza AA, van Ryn M. Economic burden for informal caregivers of lung and colorectal cancer patients. Oncologist 2010; 15:883-93.

13. van Ryn M, Sanders S, Kahn K, et al. Objective burden, resources, and other stressors among informal cancer caregivers: a hidden quality issue? Psychooncology 2011; 20:44-52.

14. Northfield $S$, Nebauer $M$. The caregiving journey for family members of relatives with cancer: how do they cope? Clin J Oncol Nurs 2010; 14:567-77.

15. Blum K, Sherman DW. Understanding the experience of caregivers: a focus on transitions. Semin Oncol Nurs 2010; 26:243-58.

16. Mazanec SR, Daly BJ, Douglas SL, Lipson AR. Work productivity and health of informal caregivers of persons with advanced cancer. Res Nurs Health 2011; 34:483-95.

17. Williams Al, Tisch AJ, Dixon J, McCorkle R. Factors associated with depressive symptoms in cancer family caregivers of patients receiving chemotherapy. Support Care Cancer 2013; 21:2387-94.

18. Chiou CJ, Chang HY, Chen IP, Wang HH. Social support and caregiving circumstances as predictors of caregiver burden in Taiwan. Arch Gerontol Geriatr 2009; 48:419-24.

19. Palos GR, Mendoza TR, Liao KP, et al. Caregiver symptom burden: the risk of caring for an underserved patient with advanced cancer. Cancer 2011; 117:1070-9.

20. Kim Y, Schulz R, Carver CS. Benefit-finding in the cancer caregiving experience. Psychosom Med 2007; 69:283-91.

21. Haley WE, LaMonde LA, Han B, Burton AM, Schonwetter R. Predictors of depression and life satisfaction among spousal caregivers in hospice: application of a stress process model. J Palliat Med 2003; 6:215-24.

22. Cañas JJ, Quesada JF, Antolí A, Fajardo I. Cognitive flexibility and adaptability to environmental changes in dynamic complex problem-solving tasks. Ergonomics 2003; 46:482-501.

23. Wagner CD, Tanmoy Das L, Bigatti SM, Storniolo AM. Characterizing burden, caregiving benefits, and psychological distress of husbands of breast cancer patients during treatment and beyond. Cancer Nurs 2011; 34:E21-30.

24. Tamayo GJ, Broxson A, Munsell M, Cohen MZ. Caring for the caregiver. Oncol Nurs Forum 2010; 37:E50-7.

25. Beck AT, Ward CH, Mendelson M, Mock J, Erbaugh J. An inventory for measuring depression. Arch Gen Psychiatry 1961; 4:561-71.

26. Beck AT, Epstein N, Brown G, Steer RA. An inventory for measuring clinical anxiety: psychometric properties. J Consult Clin Psychol 1988; 56:893-7.

27. Hisli N. [A study on the validity of Beck Depression Inventory]. Pskoloji Dergisi 1988; 6:118-22. Turkish.

28. Ulusoy M, Sahin NH, Erkmen H. Turkish version of the Beck Anxiety Inventory: Psychometric Properties. J Cogn Psychother 1998; 12:163-173.

29. Zarit SH, Reever KE, Bach-Peterson J. Relatives of the impaired elderly: correlates of feelings of burden. Gerontologist 1980; 20:649-55.

30. Özlü A, Yıldız M, Aker T. A reliability and validity study on the Zarit Caregiver Burden Scale. Arch Neuropsychiatry 2009; 46:38-42.

31. Dennis JP, Vander Wal JS. The Cognitive Flexibility Inventory: instrument development and estimates of reliability and validity. Cogn Ther Res 2010; 34:241-53.

32. Gülüm VI, Dağ I. The Turkish adaptation, validity and reliability study of the Repetitive Thinking Questionnaire and the Cognitive Flexibility Inventory. Anadolu Psikiyatri Derg 2012; 13:216-23.

33. Park B, Kim SY, Shin JY, et al. Prevalence and predictors of anxiety and depression among family caregivers of cancer patients: a nationwide survey of patient-family caregiver dyads in Korea. Support Care Cancer 2013; 21:2799-807.

34. Northouse L, Williams AL, Given B, McCorkle R. Psychosocial care for family caregivers of patients with cancer. J Clin Oncol 2012; 30:1227-34.

35. Swore Fletcher BA, Dodd MJ, Schumacher KL, Miaskowski C. Symptom experience of family caregivers of patients with cancer. Oncol Nurs Forum 2008; 35:E23-44.

36. Bedard M, Kuzik R, Chambers L, et al. Understanding burden differences between men and women caregivers: the contribution of care-recipients problem behaviors. Int Psychogeriatr 2005; 17:99-118.

37. Morris M. Gender-sensitive home and community care and caregiving research: a synthesis paper. Available at: http://www.womenandhealthcarereform.ca/ publications/synthesis.pdf. Accessed May 18, 2018.

38. Brodaty $\mathrm{H}$, Hadzi-Pavlovic D. Psychosocial effects on carers of living with persons with dementia. Aust N Z J Psychiatry 1990; 24:351-61.

39. Cohen S. Social relationships and health. Am J Psychol 2004; 59:676-84.

40. Brodaty H, Donkin M. Family caregivers of people with dementia. Dialogues Clin Neurosci 2009; 11:217-28. 
41. Connell CM, Javenic MR, Gallant MP. The costs of caring; impact of dementia on family caregivers. J Geriatr Psychiatry Neurol 2001; 14:179-87.

42. Rinaldi P, Spazzafumo L, Mastriforti R, et al; Study Group on Brain Aging of the Italian Society of Gerontology and Geriatrics. Predictors of high level of burden and distress in caregivers of demented patients: result of an Italian multicenter study. Int J Geriatr Psychiatry 2005; 20:168-74.

43. Pinquart M, Sörensen S. Differences between caregivers and noncaregivers in psychological health and physical health: a meta-analysis. Psychol Aging 2003; 18:250-67.

44. Kim Y, Duberstein PR, Sörensen S, Larson MR. Levels of depressive symptoms in spouses of people with lung cancer: effects of personality, social support, and caregiving burden. Psychosomatics 2005; 46:123-30.

45. Chou KR. Caregiver burden: a concept analysis. J Pediatr Nurs 2000; 15:398-407.

46. Kotronoulas G, Wengström Y, Kearney N. Informal carers: a focus on the real caregivers of people with cancer. Forum Clin Oncol 2012; 3:58-65.

47. Sherwood P, Given BA, Given CW, et al. A cognitive behavioral intervention for symptom management in patients with advanced cancer. Oncol Nurs Forum 2005; 32:1190-8.

48. Govina O, Kotronoulas G, Mystakidou K, et al. Effects of patient and personal demographic, clinical and psychosocial characteristics on the burden of family members caring for patients with advanced cancer in Greece. Eur J Oncol Nurs 2015; 19:81-8

49. Rende B. Cognitive flexibility: theory, assessment, and treatment. Semin Speech Lang 2000; 21:121-32; quiz 133.

50. Scott WA. Cognitive complexity and cognitive flexibility. Sociometry 1962; 25:405-14.

51. Beck AT. Cognitive Therapy and the Emotional Disorders. New York, NY: International Universities Press, 1976.

52. Beck AT. Cognitive Therapy of Depression. New York: Guildford Press, 1979.

53. Young JE, Weinberger AD, Beck AT. Cognitive Therapy for Depression. In: Barlow DH, eds. Clinical Handbook of Psychological Disorders: A Step-By-Step Treatment Manual. 3rd ed. New York: Guilford Press, 2001: 264-308.

54. Hollon SD, DeRubeis RJ, Evans MD. Cognitive Therapy in the Treatment and Prevention of Depression. In: Salkovskis PM, eds. Frontiers of Cognitive Therapy. New York: Guilford Press, 1996: 293-317.

55. Given BA, Given CW, Kozachik S. Family support in advanced cancer. CA Cancer J Clin 2001; 51:213-31.

56. Papastavrou E, Charalambous A, Tsangari H. How do informal caregivers of patients with cancer cope: a descriptive study of the coping strategies employed. Eur J Oncol Nurs 2012; 16:258-63. 